Received: 24 May 2018

Accepted: 12 July 2018

Published online: 23 July 2018

\section{Enhanced bending strength and thermal conductivity in diamond/Al composites with $\mathrm{B}_{4} \mathrm{C}$ coating}

\author{
Youhong Sun ${ }^{1,2,3}$, Chi Zhang ${ }^{1,2}$, Linkai He ${ }^{1,2}$, Oingnan Meng ${ }^{1,2}$, Bao-Chang Liu ${ }^{1,2,3}, \mathrm{Ke} \mathrm{Gao}^{1,2}$ \& \\ Jinhao $\mathrm{Wu}^{1,2}$
}

Diamond/Al composites containing $\mathrm{B}_{4} \mathrm{C}$-coated and uncoated diamond particles were prepared by powder metallurgy. The microstructure, bending strength and thermal conductivity were characterized considering the $\mathrm{B}_{4} \mathrm{C}$ addition and diamond fraction. The influence of $\mathrm{B}_{4} \mathrm{C}$ coating and fraction of diamond on both bending strength and thermal conductivity were investigated. The bending strength increased with decreasing diamond fraction. Moreover, addition of $\mathrm{B}_{4} \mathrm{C}$ coating led to an obvious increase in bending strength. The peak value at $261.2 \mathrm{MPa}$ was achieved in the composite with 30 vt.\% $\mathrm{B}_{4} \mathrm{C}$-coated diamond particles, which was about twice of that for 30 vt.\% uncoated diamond/ Al composite ( $140.1 \mathrm{MPa})$. The thermal conductivity enhanced with the increase in diamond fraction, and the highest value $(352.7 \mathrm{~W} / \mathrm{m} \cdot \mathrm{K})$ was obtained in the composite with $50 \mathrm{vt} . \% \mathrm{~B}{ }_{4} \mathrm{C}$-coated diamond particles. Plating $\mathrm{B}_{4} \mathrm{C}$ on diamond gave rise to the enhancement in bending strength and thermal conductivity for diamond/Al composites, because of the improvement of the interfacial bonding between diamond and aluminum matrix.

Metal matrix composites (MMCs) reinforced with diamond have achieved much attention in variety applications such as cut-off wheels and drills for concrete cutting, tunneling or oil exploration, due to its high hardness and grinding ability ${ }^{1-5}$. In addition, the excellent thermal conductivity (TC) and low thermal expansion of diamond reinforced MMCs make them attractive in the field of microelectronics and semiconductors ${ }^{6-9}$. The mechanical properties and thermal properties of composites are all determined by the interfacial bonding between diamond and metal matrix ${ }^{10-16}$. Recently, diamond reinforced aluminum or aluminum alloy composites have been proposed as candidate materials for above applications. However, the natural de-bonding between aluminum and the hexagonal diamond surfaces (with (1 111$)$ orientations) is not conducive to obtain a strong interfacial bonding for the transfer of stress and heat ${ }^{17}$.

Coating strong carbide formers elements on diamond is an effective approach to optimize the interfacial bonding between diamond and metal matrix. The coatings form and bond with diamond during plating process, and alloy with metal matrix during sintering process. Zhang et al. ${ }^{18}$ studied the effects of diamond volume fraction and tungsten coating on the thermal properties of diamond/Al composites. The TC for the specimens with W-coated diamond particles exhibited above $90 \%$ of the theoretical values. Feng et al. ${ }^{7}$ reported that coating TiC was benefited to the enhancement of TC for diamond/Al composites, since $\mathrm{Al}_{4} \mathrm{C}_{3}$ and $\mathrm{Ti}_{3} \mathrm{Al}$ interfacial phase were formed during heating process, resulting in an improvement of combination between TiC-coated diamond and $\mathrm{Al}$ matrix. The $\mathrm{Al}_{4} \mathrm{C}_{3}$ is, however, a well-known brittle phase, which usually lead to a low strength for $\mathrm{MMCs}^{19}$. In addition, Wu et al. found ${ }^{20}$ that the forming of $\mathrm{Ti}_{3} \mathrm{Al}$ gave rise to a decrease in tensile strength for TiC-coated diamond reinforced $\mathrm{Al}$. Thereby, for improving strength but not only TC, a more stable and strong interface was required for stress transfer.

Boron carbide $\left(\mathrm{B}_{4} \mathrm{C}\right)$ is widely used as a reinforcement particle in aluminum alloy for improving strength, hardness and wear resistance ${ }^{21-25}$. Zhang et al. ${ }^{21}$ investigated the effect of $\mathrm{B}_{4} \mathrm{C}$ content on mechanical properties of $\mathrm{B}_{4} \mathrm{C} / \mathrm{Al}$ composite, and found that $\mathrm{B}_{4} \mathrm{C}$ particles contributed to the enhancement in hardness, bending strength and tensile strength. Rana et al. ${ }^{25}$ used $7075 \mathrm{Al}$ as parent metal and $\mathrm{B}_{4} \mathrm{C}$ powder particles as reinforcement, and

${ }^{1}$ College of Construction Engineering, Jilin University, Changchun, 130026, People's Republic of China. ${ }^{2}$ Key Lab of Drilling and Exploitation Technology in Complex Conditions, Ministry of Land and Resources, Changchun, 130061, People's Republic of China. ${ }^{3}$ State Key Laboratory of Superhard Materials, Jilin University, Changchun, 130012, People's Republic of China. Correspondence and requests for materials should be addressed to Q.M. (email: qingnanmeng@jlu.edu.cn) 

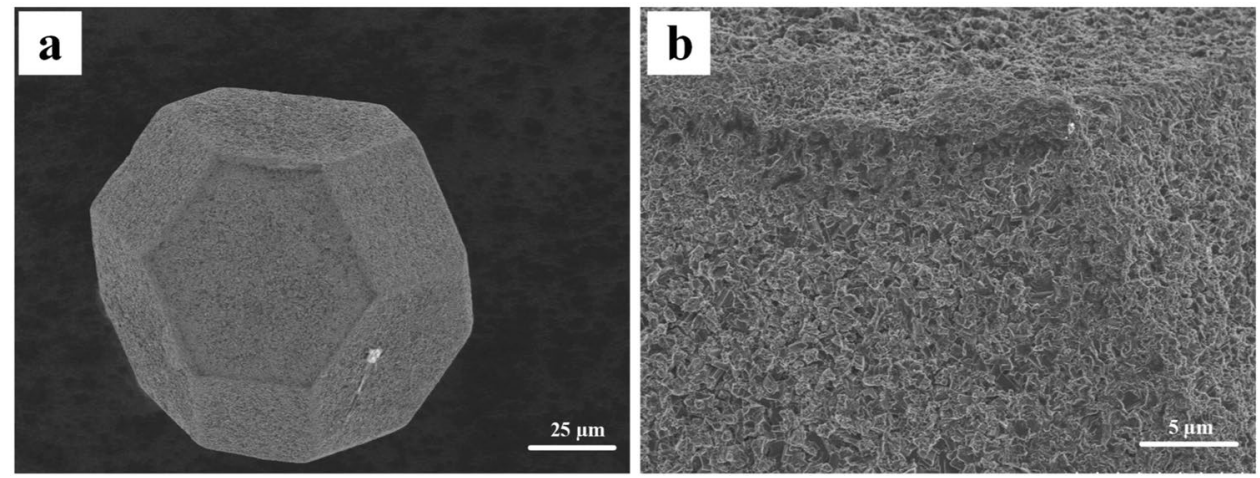

Figure 1. Morphologies for the $\mathrm{B}_{4} \mathrm{C}$-coated diamond particles.

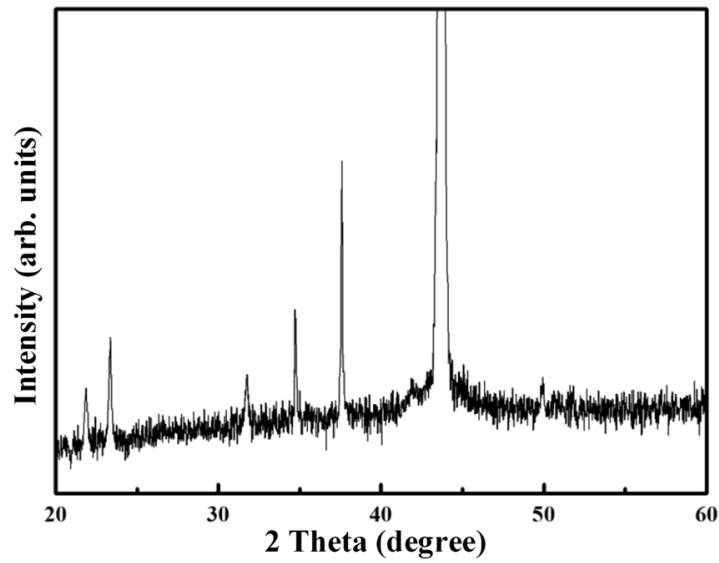

Figure 2. XRD spectrum for $\mathrm{B}_{4} \mathrm{C}$-coated diamond particle.

then fabricated $7075 \mathrm{Al} / \mathrm{B}_{4} \mathrm{C}$ surface composite through friction stir processing (FSP). A 100\% improvement in wear resistance was achieved compared to the parent metal. These results indicated that $\mathrm{Al} / \mathrm{B}_{4} \mathrm{C}$ exhibited a strong interface. Meanwhile, $\mathrm{B}_{4} \mathrm{C}$ bond with diamond via $\mathrm{B}-\mathrm{C}$ covalent bond ${ }^{26}$. Therefore, pre-plating $\mathrm{B}_{4} \mathrm{C}$ coating on diamond was a potential effective method for increasing both strength and $\mathrm{TC}$ for diamond/Al composite.

In this work, we describe the great enhancement in bending strength and TC for aluminum composites reinforced with $\mathrm{B}_{4} \mathrm{C}$-coated diamond particles. The diamond/Al composites with different volume fraction of $\mathrm{B}_{4} \mathrm{C}$-coated and uncoated diamond particles were prepared by powder metallurgy. The $\mathrm{B}_{4} \mathrm{C}$ coating on diamond is conducive to obtain a dense diamond/Al composite due to the continual bonding interface. The enhancements of both mechanical and thermal properties are dependent on the porosity and the interfacial gap width between diamond and aluminum matrix.

\section{Results}

The scanning electron microscopy (SEM) images for the $\mathrm{B}_{4} \mathrm{C}$-coated diamond particles are shown in Fig. 1. For the coated diamond, a complete coverage of coating is achieved on all faces. The $\mathrm{B}_{4} \mathrm{C}$ layer is quite homogeneous, and the magnified image (Fig. $1 \mathrm{~b}$ ) indicates that the layer consists of submicron particles. The X-ray diffractogram (XRD) spectrum for the $\mathrm{B}_{4} \mathrm{C}$-coated diamond particles is displayed in Fig. 2. As shown in Fig. 2, a high-intensity peak located at $43.9^{\circ}$ is attributed to diamond (JCPDF\#06-0675), which is partially truncated for clearly observing the other peaks for the coating on the diamond particle. Compared to the standard JCPDF\#35-0798, the diffraction peaks located at $21.9^{\circ}, 23.3^{\circ}, 31.8^{\circ}, 34.7^{\circ}, 37.6^{\circ}$ and $49.9^{\circ}$ are ascribed to the typical $\mathrm{B}_{4} \mathrm{C}$ structure. The grain sizes of the $\mathrm{B}_{4} \mathrm{C}$ coating calculated from Williamson-Hall plot is $64 \mathrm{~nm}$.

SEM micrographs of the uncoated-diamond/Al (D1-3) and coated-diamond/Al (B1-3) composites are shown in Fig. 3. It can be seen that a quite homogeneous distribution of diamond particles is achieved and most corners of diamond particles remain. For the uncoated-diamond/Al composites (D1-3, Fig. 3a,c,e), wide gap between diamond and $\mathrm{Al}$ matrix is observed. Meanwhile, un-wetting phenomenon between diamond particles and $\mathrm{Al}$ matrix is existent on the surface of uncoated-diamond/Al composites. The wide gap and un-wetting phenomenon between diamond and $\mathrm{Al}$ are more significant with the increase in diamond fraction. In contrast, for the coated-diamond/Al composites (B1-3, Fig. 3b,d,f), both amount and width of gap between diamond particles and $\mathrm{Al}$ matrix exhibit an obvious decrease. Moreover, even for the composite with $50 \mathrm{vt} . \% \mathrm{~B}_{4} \mathrm{C}$-coated diamond (B3, Fig. 3f), the un-wetting phenomenon is never observed. It indicates that the $\mathrm{B}_{4} \mathrm{C}$ coating gives rise to a good adhesion between diamond and $\mathrm{Al}$ matrix, which causes the densification of diamond/Al composites. 

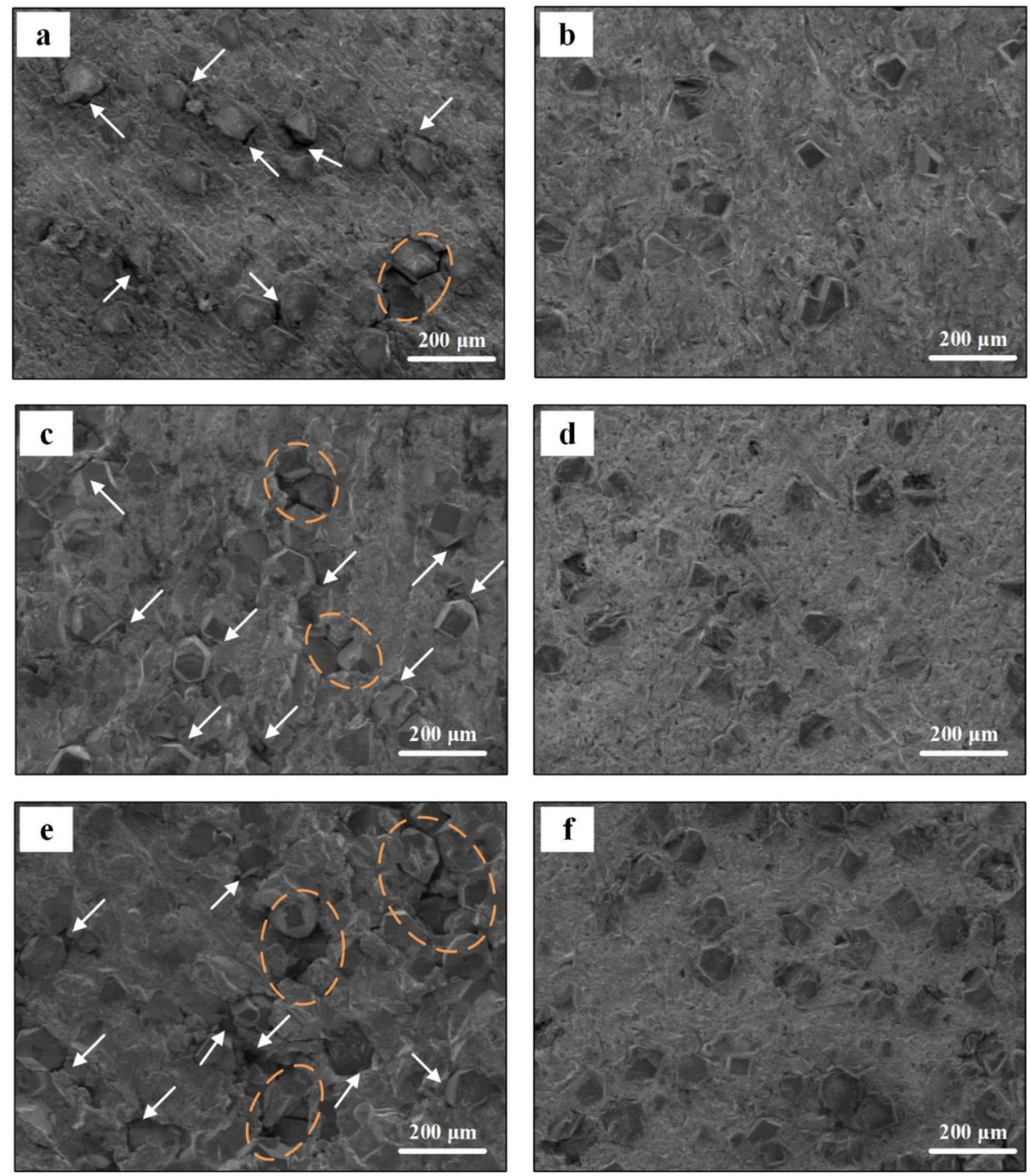

Figure 3. SEM micrographs for the diamond/Al composites with uncoated $(\mathbf{a}, \mathbf{c}, \mathbf{e})$ and $\mathrm{B}_{4} \mathrm{C}$-coated $(\mathbf{b}, \mathbf{d}, \mathbf{f})$ diamond particles with fraction of $30 \mathrm{vt} . \%(\mathbf{a}, \mathbf{b}), 40 \mathrm{vt} \%$ (c,d), and $50 \mathrm{vt} \%$ (e,f), gap between diamond and aluminum matrix and un-wetting phenomenon are highlighted with white arrows and brown circles respectively.

The distribution of the composite elements $(\mathrm{Al}$ and $\mathrm{C})$ in $\mathrm{B}_{4} \mathrm{C}$-coated-diamond/ $\mathrm{Al}$ composites is analyzed by EDS line-scanning and the results are shown in Fig. 4 . Three distinct zones ( $\mathrm{Al}$ zone, $\mathrm{B}_{4} \mathrm{C}$ layer and diamond zone) are presented in the figure. The thickness of the interfacial $\mathrm{B}_{4} \mathrm{C}$ layer is about $1.5 \mu \mathrm{m}$. When entering the interfacial $\mathrm{B}_{4} \mathrm{C}$ layer from the $\mathrm{Al}$ zone, a sharp decrease in intensity of the $\mathrm{Al}$ signal as well as an increase in intensity of $\mathrm{C}$ signal are observed. When entering the diamond zone from the interfacial $\mathrm{B}_{4} \mathrm{C}$ layer, a further increase in intensity of the $\mathrm{C}$ signal is observed, indicating the difference in the content of carbon between $\mathrm{B}_{4} \mathrm{C}$ and diamond.

Figure 5 presents the XRD patterns for the diamond/Al composites with $50 \mathrm{vt} \%$ uncoated and $\mathrm{B}_{4} \mathrm{C}$-coated diamond particles (D3 and B3). Apart from the four typical aluminum peaks at $38.5^{\circ}, 44.7^{\circ}$, $65.1^{\circ}$ and $78.2^{\circ}$ (JCPDF\#65-2869), the diamond peak is observed at $43.9^{\circ}$ (JCPDF\#06-0675). For the 50 vt.\% $\mathrm{B}_{4} \mathrm{C}$-coated-diamond/ $\mathrm{Al}$ composites (B3), typical $\mathrm{B}_{4} \mathrm{C}$ structure is confirmed by the peaks at $22.0^{\circ}, 23.5^{\circ}, 34.9^{\circ}$ and $37.8^{\circ}$ (JCPDF\#35-0798).

The theoretical density of the composte is determined by.

$$
\rho_{\text {theoretical }}=\rho_{D} V_{D}+\rho_{M} V_{M}
$$

where $\rho_{D}\left(3.52 \mathrm{~g} / \mathrm{cm}^{327}\right)$ and $\rho_{m}\left(2.70 \mathrm{~g} / \mathrm{cm}^{327}\right)$ is theoretical density of diamond and aluminum matrix, respectively. $V_{D}$ and $V_{M}$ are the volume fraction of diamond particles and aluminum matrix respectively. Thereby, the theoretical density for composite with 30,40 and $50 \mathrm{vt} . \%$ diamond is $2.95,3.03$ and $3.11 \mathrm{~g} / \mathrm{cm}^{3}$, respectively. With increasing diamond from 30 to $50 \mathrm{vt}$. $\%$, the density of uncoated-diamond/Al composites is $2.86,2.92$ and $2.96 \mathrm{~g} /$ $\mathrm{cm}^{3}$ (D1-3), which is quite lower than the corresponding theoretical density. In contrast, plating $\mathrm{B}_{4} \mathrm{C}$ coating on 


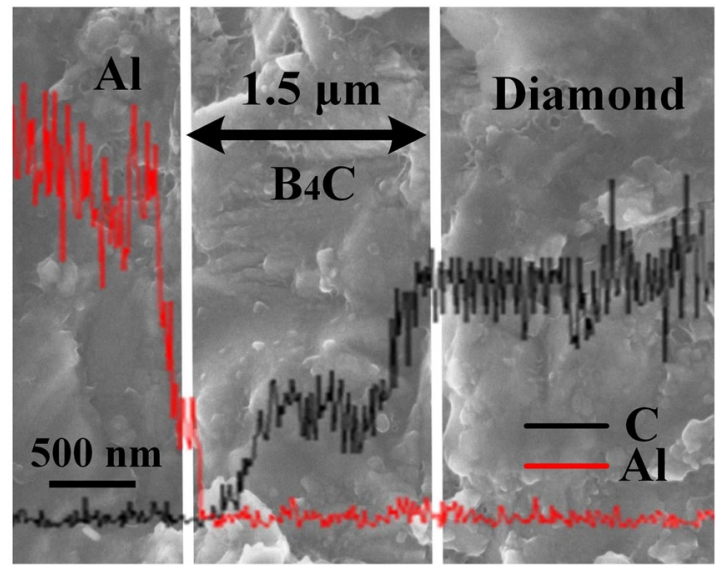

Figure 4. EDS interface line-scan in $\mathrm{B}_{4} \mathrm{C}$-coated-diamond/ $\mathrm{Al}$ composites.

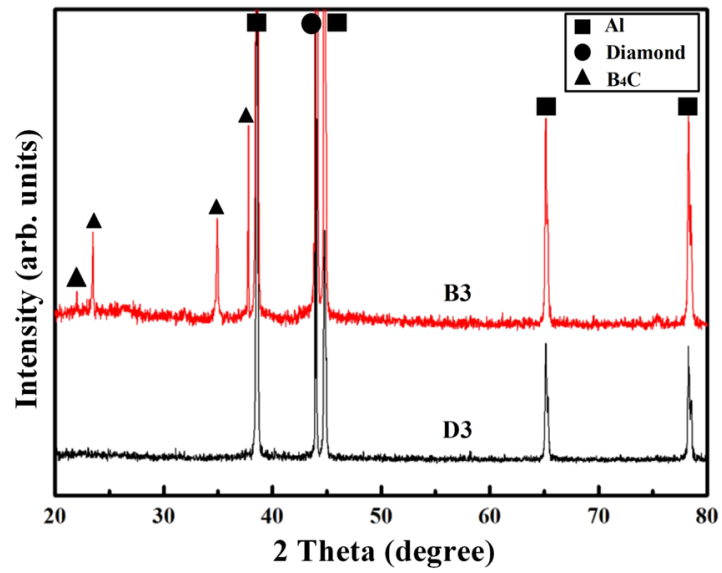

Figure 5. XRD patterns for diamond/Al composites containing $50 \mathrm{vt} . \%$ uncoated and $\mathrm{B}_{4} \mathrm{C}$-coated diamond particles.

diamond gives rise to dense composites. The composite with $30 \mathrm{vt} . \% \mathrm{~B}_{4} \mathrm{C}$-coated diamond (B1) exhibits a density of $2.92 \mathrm{~g} / \mathrm{cm}^{3}$, which is quite close to the theoretical density. The composite with $50 \mathrm{vt} . \% \mathrm{~B}_{4} \mathrm{C}$-coated diamond particles (B3) still maintains a high density $\left(3.05 \mathrm{~g} / \mathrm{cm}^{3}\right)$, which is denser than all uncoated-diamond/Al composites (D1-3). The relative density $\rho_{\text {relative }}$ is determined by.

$$
\rho_{\text {relative }}=\rho_{\text {measured }} / \rho_{\text {theoretical }}
$$

where $\rho_{\text {measured }}$ is the measured density. The relative densities for Al/diamond composites with different diamond fractions of uncoated and $\mathrm{B}_{4} \mathrm{C}$-coated diamond particles are shown in Fig. 6. As shown in Fig. 6, the relative densities for composites with both uncoated and $\mathrm{B}_{4} \mathrm{C}$ coated diamond particles decrease with the increase in diamond fraction, whereas the relative densities for composites with $\mathrm{B}_{4} \mathrm{C}$ coated diamond particles $(>97.9 \%)$ are higher than those for composites with uncoated diamonds (up to 97.2\%). Furthermore, by comparing relative density for the $\mathrm{B}_{4} \mathrm{C}$-coated-diamond/ $\mathrm{Al}$ with that for the corresponding uncoated-diamond/Al composite, the improvement in relative density increases from 1.8 to $2.6 \%$ with increasing diamonds fraction from 30 to 50 vt. $\%$, meaning that plating $\mathrm{B}_{4} \mathrm{C}$ coating on diamond is benefit to the densification of diamond/Al composite.

Figure 7 displays the bending strength obtained by the three-point bending tests. For all composites, the increase in diamond fraction results in a decrease in bending strength. The bending strength for uncoated-diamond/Al composite decreases from 140.1 to $90.8 \mathrm{MPa}$ with increasing diamond fraction from 30 to $50 \mathrm{vt} . \%$. It is worth noted that the bending strength for the $\mathrm{B}_{4} \mathrm{C}$-coated diamond/Al composites are much higher than that for the uncoated diamond/ $\mathrm{Al}$ composites. The composite with $30 \mathrm{vt} \% \mathrm{~B}_{4} \mathrm{C}$ coated diamond particles (B1) exhibits the largest bending strength (261.2 MPa), which increases by $86.4 \%$ compared with the corresponding composite with $30 \mathrm{vt}$. \% uncoated diamond particles (D1). In addition, the bending strength for composite with 50 vt. $\% \mathrm{~B}_{4} \mathrm{C}$ coated diamond particles (B3) is $192.4 \mathrm{MPa}$, which is over twice of that for composite with 50 vt. \% uncoated diamond particles (D3, 90.8 MPa) and even larger than that for composite with 30 vt. \% uncoated diamond particles (D1, 140.1 MPa). 


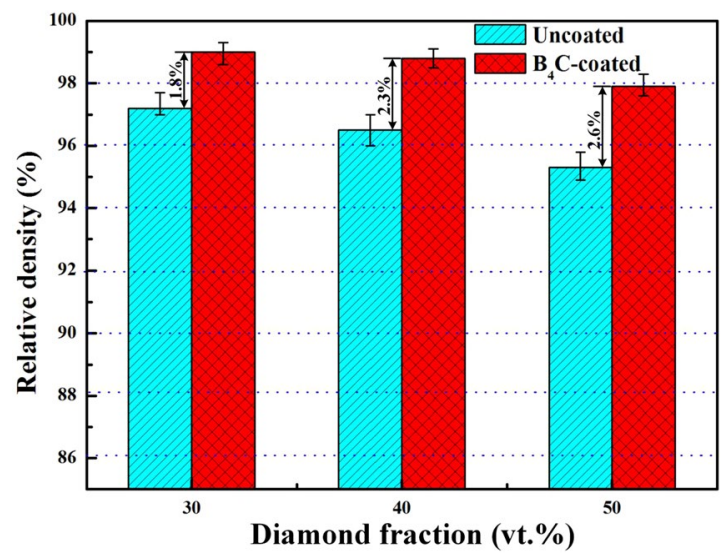

Figure 6. Relative density of the diamond/Al composites with uncoated and $\mathrm{B}_{4} \mathrm{C}$-coated diamond particles as a function of fraction.

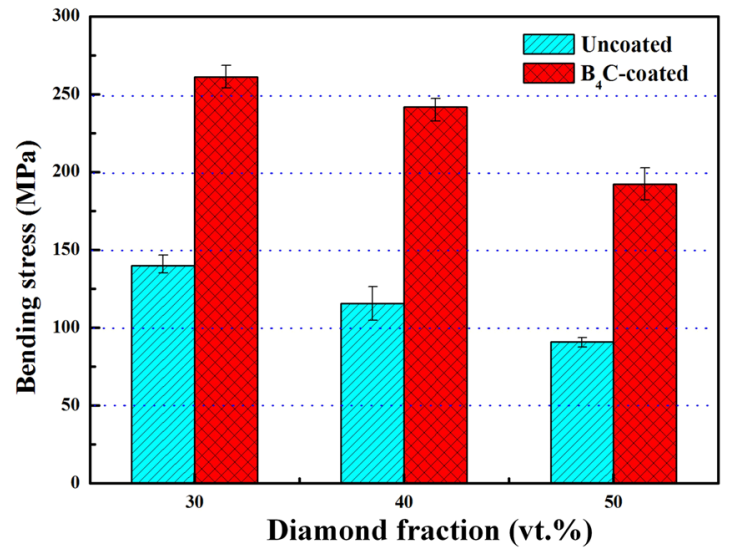

Figure 7. The bending strength of $\mathrm{B}_{4} \mathrm{C}$-coated and uncoated diamond/Al composites with different diamond fractions obtained by three-point bending tests.

SEM micrographs for bending fracture surfaces of the diamond/Al composites with uncoated (D1-3) and $\mathrm{B}_{4} \mathrm{C}$-coated (B1-3) diamond particles are given in Fig. 8. For the uncoated-diamond/Al composites (D1-3, Fig. 8a,c,e), large amounts of wide gap around diamond particles are observed, which is marked by white arrows. Meanwhile, un-wetting phenomenon between aluminum matrix and diamond particles is existent, which is highlighted by brown arrows. For the $\mathrm{B}_{4} \mathrm{C}$-coated-diamond/Al composites (B1-3, Fig. 8b,d,f), no obvious gap around diamond particles is found. EDS mapping was used to evaluate the bonding condition between diamond particles and aluminum matrix. Figure 9 presents the elements distribution maps of diamond/Al composites containing 50 vt.\% uncoated and $\mathrm{B}_{4} \mathrm{C}$-coated diamond particles. As shown in Fig. 9a,b, obvious gap at the interface boundary is observed for the uncoated-diamond/Al composite (D3). Meanwhile, most surfaces of the diamond particle remain naked without aluminum matrix surrounded, indicating a poor interfacial bonding caused by the un-wetting between diamond and aluminum matrix. It implies the fracture of composite D3 occurred from interface between diamond and $\mathrm{Al}$ matrix, because of the poor interfacial bonding. According to the elements distribution map of sample B3 (Fig. 9c,d), the adhesion of the aluminum matrix to the diamond particle is remarkably improved. Most diamond surfaces are found to be embedded in the aluminum matrix, while the exposed part is covered by large amounts of aluminum dimples. It indicates that ductile fracture of Al matrix has replaced interfacial fracture to be the dominant fracture mode in composite B3, since better wettability and interfacial bonding between diamond particles and aluminum achieved by plating $\mathrm{B}_{4} \mathrm{C}$.

Figure 10 shows the TC of diamond/Al composites with uncoated (D1-3) and $\mathrm{B}_{4} \mathrm{C}$-coated (B1-3) diamond particles. As shown in Fig. 10, uncoated-diamond/Al composites (D1-3) exhibit lower TC, and the TC for sample $\mathrm{D} 1(208.4 \mathrm{~W} / \mathrm{m} \cdot \mathrm{K})$ is even lower than that for pure aluminum $\left(237 \mathrm{~W} / \mathrm{m} \cdot \mathrm{K}^{28}\right)$. With increasing diamond fraction from 30 to $50 \mathrm{vt}$. $\%$, the TC for uncoated-diamond/Al composite increases from 208.4 to $283.8 \mathrm{~W} / \mathrm{m} \cdot \mathrm{K}$, meanwhile that for $\mathrm{B}_{4} \mathrm{C}$-coated-diamond/Al composite increases from 311.4 to $352.7 \mathrm{~W} / \mathrm{m} \cdot \mathrm{K}$. Moreover, it should be noted that $\mathrm{B}_{4} \mathrm{C}$ coating gives rise to an obvious increase in thermal conductivity, because the $\mathrm{TC}$ for $\mathrm{B}_{4} \mathrm{C}$-coated diamond/Al composites are much higher than those for uncoated diamond/Al composites. The TC for composite containing $30 \mathrm{vt} . \% \mathrm{~B}_{4} \mathrm{C}$-coated diamond particles (B1) even performs better than that for the composite with 50 vt.\% uncoated diamond particles (D1). 

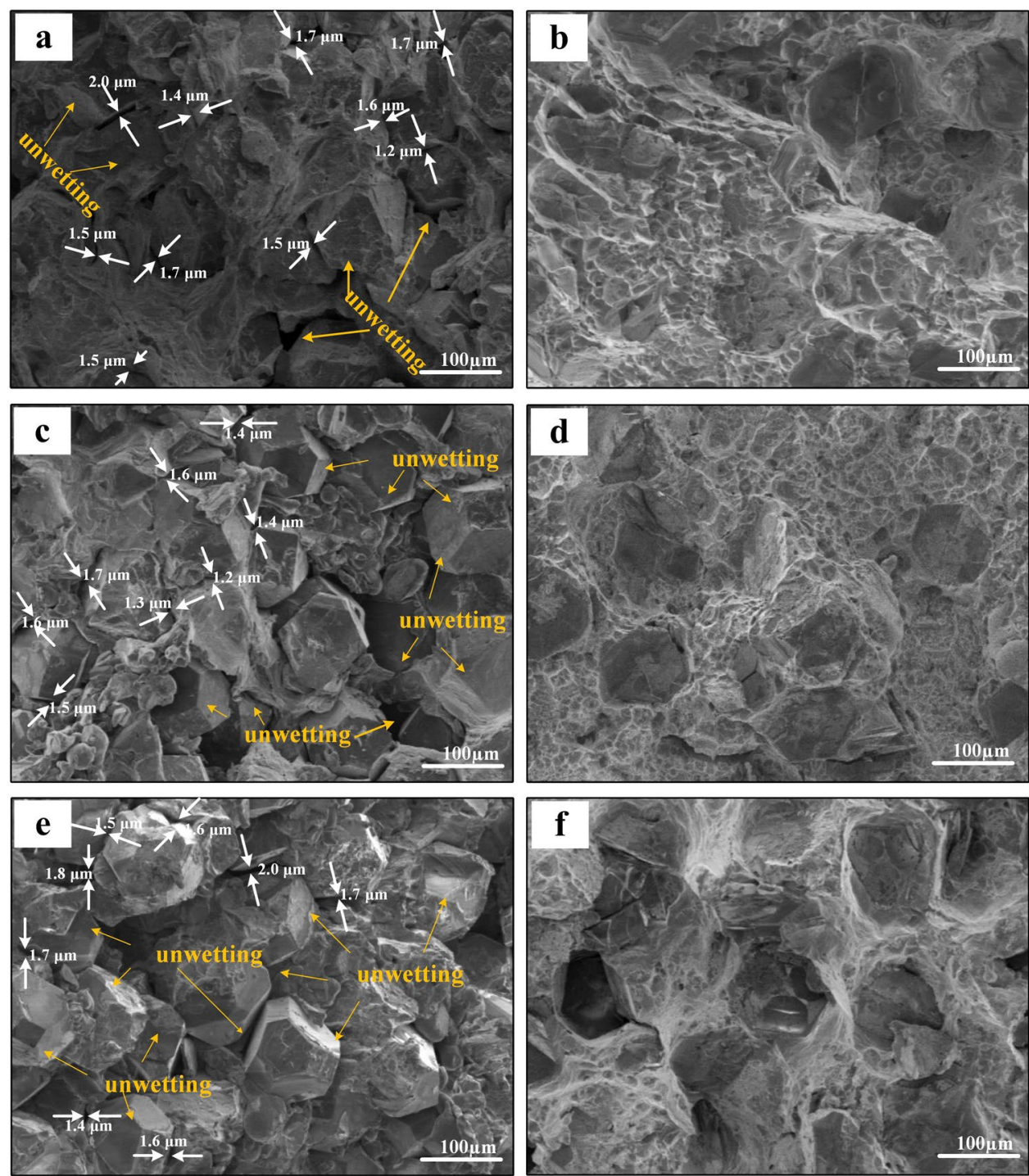

Figure 8. SEM images for the bending fracture surfaces of the diamond/Al composites with uncoated (a,c,e) and $\mathrm{B}_{4} \mathrm{C}$-coated $(\mathbf{b}, \mathbf{d}, \mathbf{f})$ diamond particles with fractions of 30 vt. $\%(\mathbf{a}, \mathbf{b}), 40 \mathrm{vt} . \%(\mathbf{c}, \mathbf{d})$, and 50 vt.\% (e,f).

\section{Discussion}

As shown in Fig. 6, the relative density for uncoated diamond/Al composites (D1-3) is lower than that for $\mathrm{B}_{4} \mathrm{C}$-coated diamond/Al composites (B1-3) at each diamond fraction, indicating that a larger number of pores exist in samples D1-3. Meanwhile, SEM images for bending fracture surface show that wider interfacial gap is observed between uncoated diamond and aluminum matrix. The separation between diamond and aluminum is caused during the cooling process by the large difference in expansion coefficients between aluminum $\left(23.0 \times 10^{-6} \mathrm{~K}^{-129}\right)$ and carbon materials $\left(1.0 \times 10^{-6} \mathrm{~K}^{-127}\right)$. Therefore, the low density for uncoated diamond/ $\mathrm{Al}$ composites is attributed to large amounts of wide gap around diamond particles. Moreover, the decrease in relative density for uncoated diamond/Al composite with the increase in diamond fraction is caused by the larger amount of wide gap provided by longer interface. Assuming that the diamond used in this study is isotropic spherical particle, the average gap width $(\mathrm{x})$ can be evaluated by

$$
\begin{aligned}
\frac{a^{3}}{(a+x)^{3}} & =\frac{\left(1-V_{p}\right) V_{D}}{\left(1-V_{p}\right) V_{D}+V_{p}} \\
V_{P} & =1-\rho_{\text {relative }}
\end{aligned}
$$

where a is the radius of diamond particle, $V_{D}$ is the volume fraction of diamond particle, and $V_{P}$ is porosity (Fig. 11a). As displayed in Fig. 11b, plating $\mathrm{B}_{4} \mathrm{C}$ coating on diamond reinforcement gives rise to a decrease in average gap width from 1.54 to $0.58 \mu \mathrm{m}$, which agrees well with SEM results (Fig. 8). $\mathrm{B}_{4} \mathrm{C}$ interlayer is benefited to relieve the interfacial thermal stress between aluminum and diamond during the cooling process due to the 

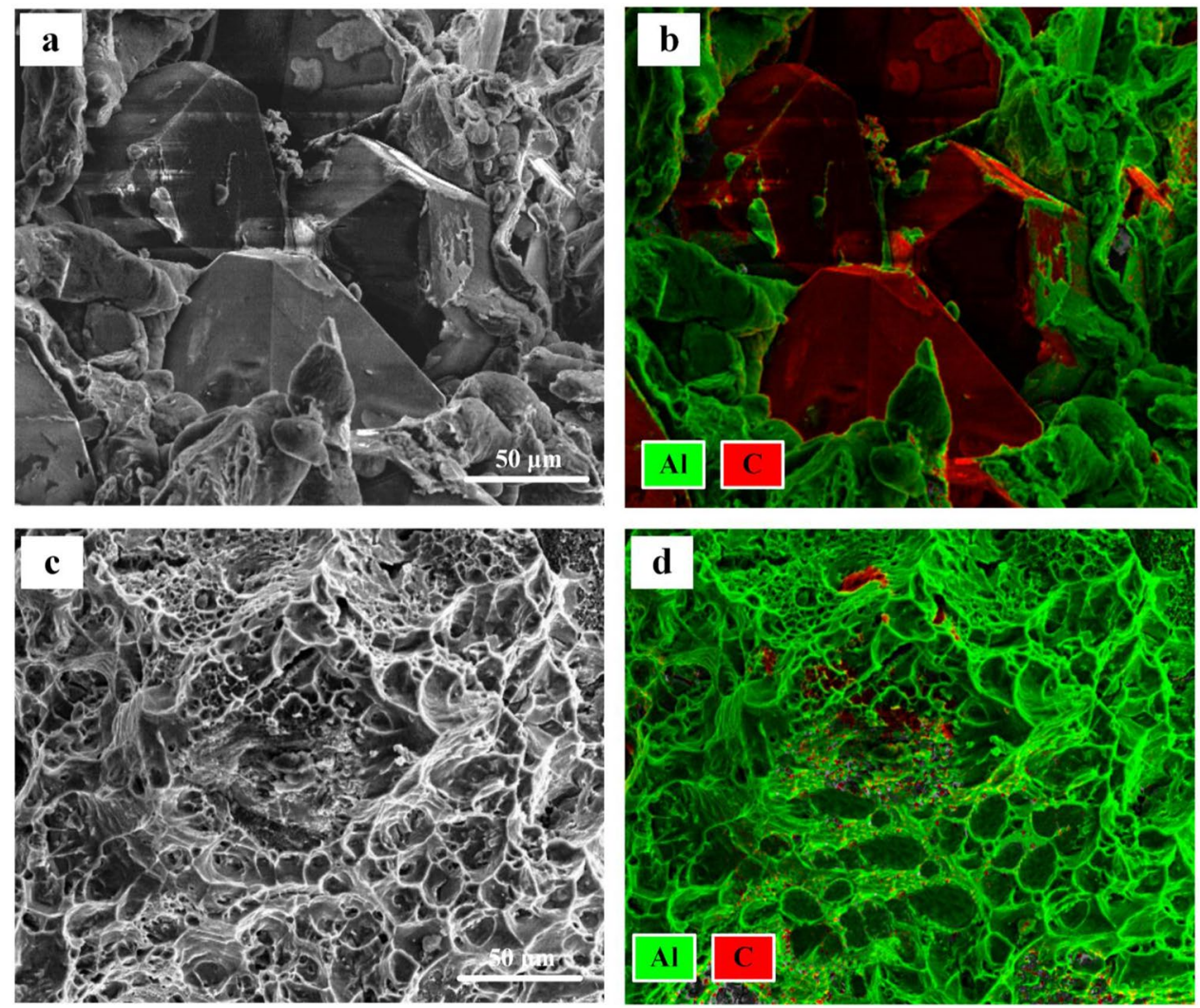

Figure 9. The elements distribution maps of the samples D3 and B3.

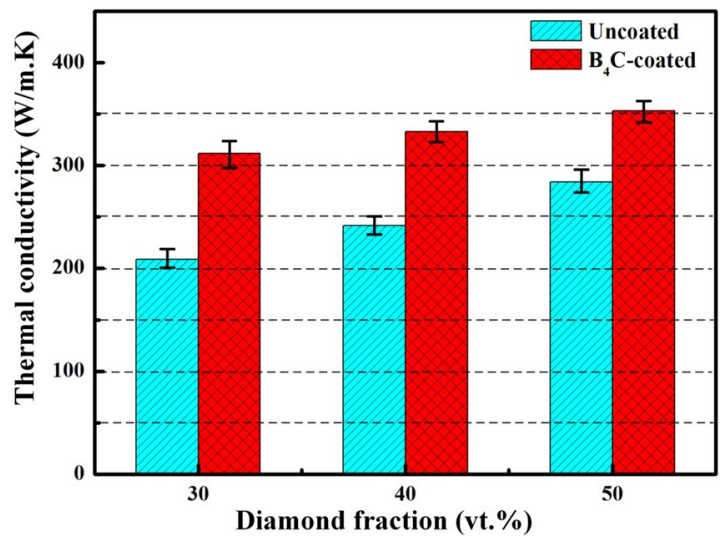

Figure 10. Thermal conductivity of diamond/ $\mathrm{Al}$ composites with uncoated and $\mathrm{B}_{4} \mathrm{C}$-coated diamond particles.

modest expansion coefficients of $\mathrm{B}_{4} \mathrm{C}\left(5.65 \times 10^{-6} \mathrm{~K}^{-130}\right)$. In addition, the improvement rate attributed to $\mathrm{B}_{4} \mathrm{C}$ interface is more significant for the composite with larger diamond fraction. Therefore, we suggest that the formation of $\mathrm{B}_{4} \mathrm{C}$ is benefited to the densification of diamond/Al composite.

Figure 12 summarizes the relationship between bending strength and porosity. It can be seen that the bending strength is strongly dependent on the porosity of diamond/Al composites. Together with the average gap width (Fig. 11) and SEM images (Fig. 8), uncoated-diamond/Al composites (D1-3) are fabricated with high porosity along with a large number of gap and pores, which contributes to the extension of the crack under stress. Therefore, the significant decrease in bending strength for uncoated diamond/Al composites with the increase in diamond fraction (as shown in Fig. 7) is due to that the larger diamond fraction results in a longer weak interface and larger number of gap and pores. For the $\mathrm{B}_{4} \mathrm{C}$-coated diamond/Al composites (B1-3), plating $\mathrm{B}_{4} \mathrm{C}$ on diamond contributes to improve the wettability between diamond and aluminum matrix and optimize the interface structure. $\mathrm{B}_{4} \mathrm{C}$ coating is benefited to the increase in bending strength due to the decrease in average gap width and porosity. For the $30 \mathrm{vt} . \% \mathrm{~B}_{4} \mathrm{C}$-coated-diamond/Al composite (B1), no obvious gap between diamond and aluminum matrix is observed and the highest bending strength is achieved, because the continual interface is 

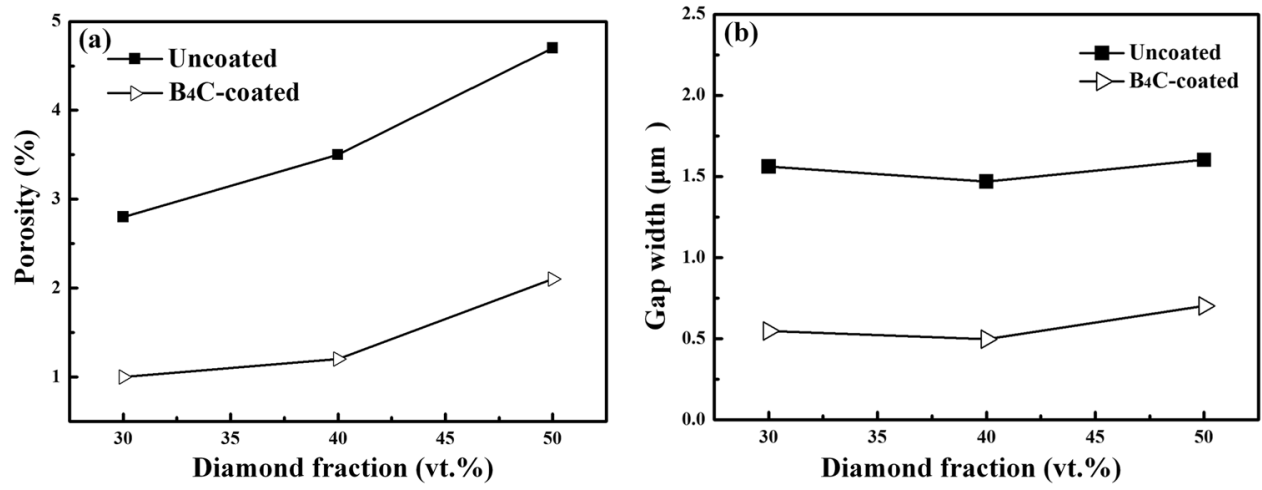

Figure 11. (a) Porosity and (b) calculated gap width for uncoated and $\mathrm{B}_{4} \mathrm{C}$-coated diamond/Al composites with different diamond fractions.

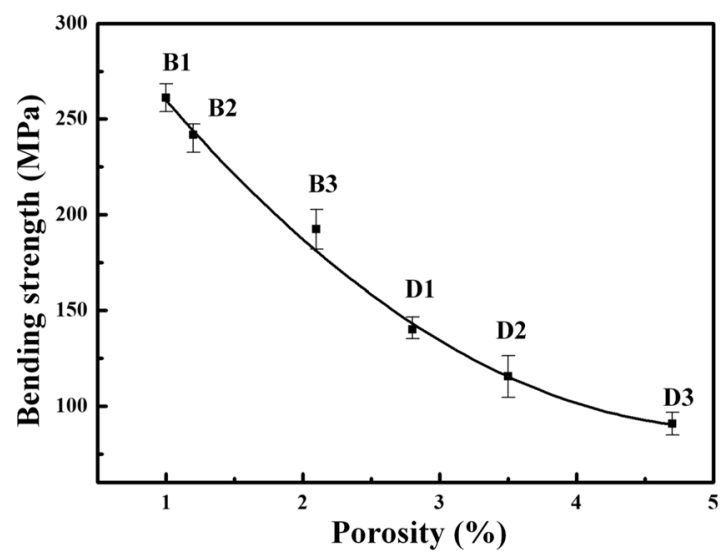

Figure 12. The relationship between bending and porosity.

conducive to distribution of stress. Thereby the enhancement is more evident for the composite with larger diamond fraction, since longer weak interface between naked diamond and $\mathrm{Al}$ matrix is enhanced by $\mathrm{B}_{4} \mathrm{C}$ interface. Furthermore, the 50 vt.\% $\mathrm{B}_{4} \mathrm{C}$-coated-diamond/ $\mathrm{Al}$ composite (B3) still maintain a high bending strength which is even larger than the bending strength for the composite with $30 \mathrm{vt} \%$ uncoated diamond particles (D1), because the number of gap and pores for $\mathrm{B} 3$ is lower than that for $\mathrm{D} 1$ via adding a $\mathrm{B}_{4} \mathrm{C}$ interlayer between diamond and Al matrix.

Furthermore, the EDS mapping results reveal the conversion of fracture behavior of diamond/Al composites after plating $\mathrm{B}_{4} \mathrm{C}$ on diamond particles. The dominant position of interfacial fracture (Fig. $9 \mathrm{~b}$ ) suggests a weak interfacial bonding between diamond and $\mathrm{Al}$ matrix for uncoated-diamond/Al composites, which is not benefited to the stress transfer and leads to a lower bending strength and brittle fracture. In contrast, for the composite with $\mathrm{B}_{4} \mathrm{C}$-coated diamond (e.g. B3), large number of dimples are observed on the surface of diamond, which is confirmed to be $\mathrm{Al}$ by $\mathrm{EDS}$ analysis. It demonstrates that the fracture mode of $\mathrm{B}_{4} \mathrm{C}$-coated-diamond/ $\mathrm{Al}$ composite is converted to ductile fracture, and a strong interfacial bonding between diamond particles and aluminum are achieved by plating $\mathrm{B}_{4} \mathrm{C}$.

As shown in Fig. 10, plating $\mathrm{B}_{4} \mathrm{C}$ on diamond particles contributes to a significant increase in TC for diamond/ $\mathrm{Al}$ composites. The TC for composites depends on many factors, such as component, reinforcement fraction and size, distribution, and interfacial bonding between the matrix and reinforcement ${ }^{18}$. To better understand the thermal conductivity behavior of diamond/Al composites, it is necessary to compare experimental results with theoretical predictions. Among those models developed by researchers, the Hasselman-Johnson (H-J) model ${ }^{31}$ was used to estimate effective thermal conductivity of composites $K_{c}$ by taking interfacial thermal barrier into consideration.

$$
K_{C}=K_{m}\left(\frac{2\left(\frac{K_{r}}{K_{m}}-\frac{K_{r}}{a h_{c}}-1\right) V_{r}+\frac{K_{r}}{K_{m}}+\frac{2 K_{r}}{a h_{c}}+2}{\left(1-\frac{K_{r}}{K_{m}}+\frac{K_{r}}{a h_{c}}\right) V_{r}+\frac{K_{r}}{K_{m}}+\frac{2 K_{r}}{a h_{c}}+2}\right)
$$




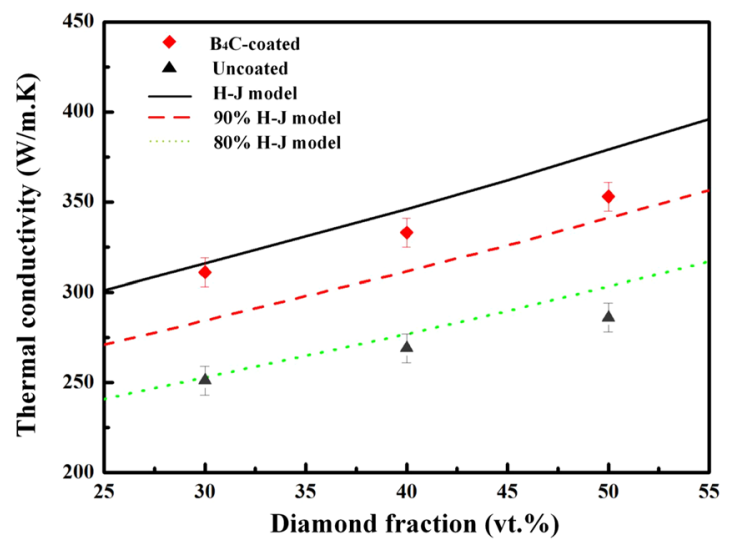

Figure 13. Variation in thermal conductivity of the diamond/ $\mathrm{Al}$ composites containing uncoated and $\mathrm{B}_{4} \mathrm{C}$ coated diamond particles.

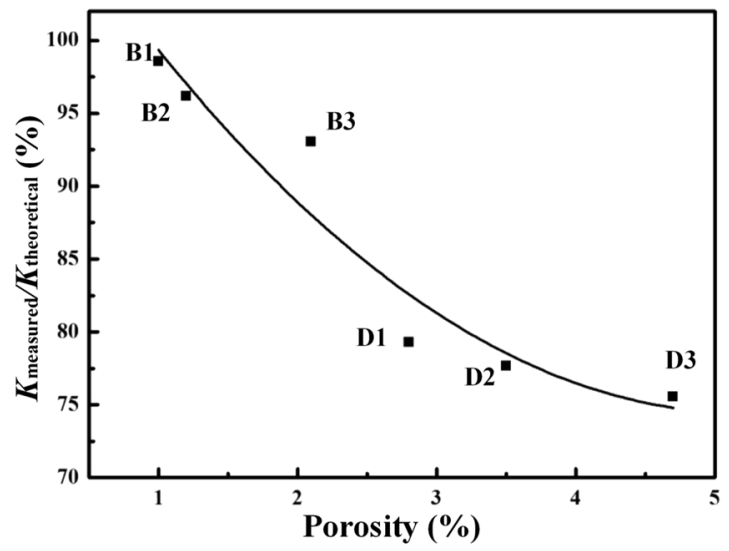

Figure 14. The relationship between $K_{\text {measured }} / K_{\text {theoretical }}$ and porosity.

where $\mathrm{K}_{\mathrm{m}}$ and $\mathrm{K}_{\mathrm{r}}$ are TC of matrix and reinforcement particles respectively $\left(\mathrm{K}_{\mathrm{Al}}=237 \mathrm{~W} / \mathrm{m} \cdot \mathrm{K}^{32}, \mathrm{~K}_{\mathrm{diamond}}=\right.$ $1350 \mathrm{~W} / \mathrm{m} \cdot \mathrm{K}^{7}$ ), a is the radius of reinforcement particle. The interfacial thermal conductance $h_{c}$ is identified as

$$
h_{C}=\frac{1}{2} \rho_{m} c_{m} \frac{v_{m}{ }^{3}}{v_{r}{ }^{2}} \frac{\rho_{m} \rho_{r} v_{m} v_{r}}{\left(\rho_{m} v_{m}+\rho_{r} v_{r}\right)^{2}}
$$

where $\rho_{m}$ and $\rho_{r}$ are theoretical density of matrix and reinforcement particle respectively, $v_{m}$ and $v_{r}$ are phonon velocity in matrix and reinforcement particle respectively $\left(v_{A l}=3040 \mathrm{~m} / \mathrm{s}, v_{\text {diamond }}=13924 \mathrm{~m} / \mathrm{s}^{26}\right)$, and $c_{m}$ is the specific heat of matrix $\left(C_{A l}=880 \mathrm{~J} / \mathrm{kg} \cdot \mathrm{K}^{7}\right)$.

The experimental data and theoretical prediction of the TC of diamond/Al composites with uncoated and $\mathrm{B}_{4} \mathrm{C}$-coated diamond particles are displayed in Fig. 13. As shown in Fig. 13, measured TCs of $\mathrm{B}_{4} \mathrm{C}$-coated-diamond/ $\mathrm{Al}$ composites are close to theoretical values, whereas for uncoated-diamond/Al composites measured TCs exhibit a clear difference with theoretical results. Near $100 \%$ of the theoretical value $(316.1 \mathrm{~W} / \mathrm{m} \cdot \mathrm{K})$ is reached for the $30 \mathrm{vt} . \% \mathrm{~B}_{4} \mathrm{C}$-coated-diamond/ $\mathrm{Al}$ composite $(\mathrm{B} 1,311.4 \mathrm{~W} / \mathrm{m} \cdot \mathrm{K})$, while only around $80 \%$ of the theoretical value is reached for D1 with uncoated diamond particles. In addition, it is worth noted in Fig. 13 that with the diamond fraction increasing, the deviation between the measured TC and theoretical value becomes larger, which is hard to be explained through the H-J model.

Although many factors are taken in the H-J model to evaluate the TC of composites, the porosity in theses specimens is not taken into consideration. It is well known that air (or vacuum) is an excellent heat insulation layer. Furthermore, the influence of porosity on TC was investigated in diamond/Cu composites ${ }^{26}$. Therefore, the existence of gap in composite contributed to the deterioration in TC of composite, leading to a larger deviation between measured and theoretical results. To further understand the effect of porosity on the TC of diamond/ $\mathrm{Al}$ composites, The relationship between $\mathrm{K}_{\text {measured }} / \mathrm{K}_{\text {theoretical }}$ and porosity for all composites is displayed in Fig. 14 . It reveals that $\mathrm{K}_{\text {measured }} / \mathrm{K}_{\text {theoretical }}$ is highly dependent on the porosity of diamond/Al composites. The measured $\mathrm{TC}$ of diamond/Al composite is closer to the theoretical prediction by the H-J model with a higher density. The relative density of diamond/Al composites (Fig. 6) suggests that the relative density decreases with increasing diamond fraction. Thereby, lower fraction of diamond in composite gives rise to an increase in $\mathrm{K}_{\text {measured }} / \mathrm{K}_{\text {theoretical }}$ 


\begin{tabular}{|l|l|l|l|}
\hline \multicolumn{2}{|l|}{ B $_{4}$ C-coated } & Uncoated \\
\hline Volume fraction (\%) & Sample number & Volume fraction (\%) & Sample number \\
\hline 30 & B1 & 30 & D1 \\
\hline 40 & B2 & 40 & D2 \\
\hline 50 & B3 & 50 & D3 \\
\hline
\end{tabular}

Table 1. Sample numbers for $\mathrm{B}_{4} \mathrm{C}$-coated and uncoated-diamond/Al composites.

\begin{tabular}{|l|l|l|l|l|}
\hline Sample & $\begin{array}{l}\text { Density } \\
\left(\mathbf{g} / \mathbf{c m}^{3}\right)\end{array}$ & $\begin{array}{l}\text { Specific } \\
\text { heat }(\mathbf{J} / \mathbf{g} \cdot \mathbf{K})\end{array}$ & $\begin{array}{l}\text { Thermal diffusivity } \\
\left(\mathbf{m m}^{2} / \mathbf{s}\right)\end{array}$ & $\begin{array}{l}\text { Thermal conductivity } \\
(\mathbf{W} / \mathbf{m} \cdot \mathbf{K})\end{array}$ \\
\hline D1 & 2.86 & 0.76 & 95.9 & 208.4 \\
\hline D2 & 2.92 & 0.71 & 115.9 & 240.3 \\
\hline D3 & 2.96 & 0.67 & 144.4 & 286.4 \\
\hline B1 & 2.92 & 0.77 & 139.0 & 312.5 \\
\hline B2 & 2.99 & 0.73 & 152.3 & 332.4 \\
\hline B3 & 3.04 & 0.69 & 168.6 & 353.7 \\
\hline
\end{tabular}

Table 2. Thermal conductivity measurements of diamond/Al composites.

(Fig. 14) because of the decrease in porosity. In addition, combined with densification and TC analyze, the addition of $\mathrm{B}_{4} \mathrm{C}$ interlayer is contributed to the densification of composite, and benefit to achieve a continual interface between diamond reinforcement and $\mathrm{Al}$ matrix, which gives rise to an obvious enhancement in thermal conductivity. Therefore, the composites with a $\mathrm{B}_{4} \mathrm{C}$ interlayer display higher TCs (Fig. 10) and larger $\mathrm{K}_{\text {measured }} / \mathrm{K}_{\text {theoretical }}$ (Fig. 14).

To summarize, diamond/Al composites with different fraction of uncoated and $\mathrm{B}_{4} \mathrm{C}$-coated diamond particles were prepared by powder metallurgy. Interfacial bonding and porosity were found to be the key factors in determining the properties of diamond/Al composites. The addition of $\mathrm{B}_{4} \mathrm{C}$ coating was benefit to the decrease in interfacial gap between diamond and $\mathrm{Al}$, which gave rise to a dense composite. In addition, both bending strength and thermal conductivity of composites were dependent on the interfacial gap width between diamond and $\mathrm{Al}$ matrix. The bending strength for composites with $\mathrm{B}_{4} \mathrm{C}$ coated diamond was about twice of that for composites with un-coated diamond. Meanwhile, the specimens with $\mathrm{B}_{4} \mathrm{C}$-coated diamond particles exhibited high TC (up to $352.7 \mathrm{~W} / \mathrm{m} \cdot \mathrm{K}$ ), even the sample with $30 \mathrm{vt} . \% \mathrm{~B}_{4} \mathrm{C}$-coated diamond exhibited a TC as $311.4 \mathrm{~W} / \mathrm{m} \cdot \mathrm{K}$, which is quite larger than that for composite with un-coated diamond (up to $283.8 \mathrm{~W} / \mathrm{m} \cdot \mathrm{K}$ ) and pure $\mathrm{Al}\left(237 \mathrm{~W} / \mathrm{m} \cdot \mathrm{K}^{28}\right.$ ).

\section{Method}

As the composite matrix, the pure aluminum powder with an average size of $74 \mu \mathrm{m}$ was provided from Shanghai Chaowei Nanotechnology Co. Ltd., China. Synthetic HPHT diamond particles (HSD90, particle size 140/170 mesh $(89 \sim 104 \mu \mathrm{m})$, Henan huanghe whirlwind international Co., Ltd., China) with cubic-octahedral monocrystalline were used as the reinforcement. For forming boron carbide $\left(\mathrm{B}_{4} \mathrm{C}\right)$ coating on diamond particles, the mixture of boron (B), boric acid $\left(\mathrm{H}_{3} \mathrm{BO}_{3}\right)$ and diamond particles was heated in a tube furnace at $1200^{\circ} \mathrm{C}$ for $6 \mathrm{~h}$ in $\mathrm{Ar}$ atmosphere. The method was described in detail in the previous work ${ }^{26}$. Different fraction of diamonds $(30,40$ and $50 \mathrm{vt} . \%$ ) were mechanically mixed with aluminum powder at room temperature. For comparison, the uncoated and $\mathrm{B}_{4} \mathrm{C}$-coated diamond particles were both applied. The powder mixtures were then subjected to vacuum hot pressing in a graphite die. The furnace was heated up to $600^{\circ} \mathrm{C}$ at a heating speed of $10^{\circ} \mathrm{C} / \mathrm{min}$, then held for $30 \mathrm{~min}$ under a uniaxial pressure at $30 \mathrm{MPa}$ in order to ensure the density. The temperature during hot pressing was monitored through a thermocouple inserted into the graphite die. After sintering, the specimens were cooled in furnace to the room temperature. The vacuum was needed before the specimens being cooled to room temperature. The composites with different fractions of $\mathrm{B}_{4} \mathrm{C}$-coated and un-coated diamond reinforcements were referred as B1-3 and D1-3 respectively, as shown in Table 1.

To investigated the microstructure of coating and the interfacial product, X-ray diffraction (XRD) was performed on a Bruker D8 with a $\mathrm{Cu} \mathrm{K} \alpha$ source in the step mode from $20^{\circ}$ to $80^{\circ}$ at a scanning speed of $0.08 \%$ s. A Hitachi S-4800 scanning electron microscope (SEM) was used to characterize the distribution of diamond particles in composites. The density of composites was measured by a high precision ceramic porosity volume density tester (Dahometer, DE-120M) using Archimedes method ${ }^{29}$. Three-point bending strength was measured on the specimens with a dimension of $5 \times 8 \times 50 \mathrm{~mm}$. The bending test was carried out with an initial speed of $0.50 \mathrm{~mm} /$ min using an electronic universal test machine (DDL 100, CIMACH, Changchun, China). The morphologies of fracture surfaces were also obtained by SEM. X-ray energy dispersive spectrometer (EDS) attached to the SEM equipment was applied to analyze the elements distribution on the fracture surface of composites. Thermal diffusivity of the composites at room temperature was measured by a laser flash method by a NETZSCH LFA427/3/G thermal physical testing instrument. Specific heat of the composites was derived from the theoretical value calculated according to the rule of mixture (ROM). Finally, the thermal conductivity was calculated by the product of density, thermal diffusivity and specific heat according to the following equation ${ }^{28}$ : 


$$
\lambda=\alpha \rho_{\text {measured }} C
$$

where $\alpha$ was thermal diffusivity, $\rho_{\text {measured }}$ was the measured density of composites and $\mathrm{C}$ was specific heat. Detailed results were shown in Table 2.

\section{References}

1. Li, M. et al. Fabrication of Fe-Based Diamond Composites by Pressureless Infiltration. Materials 9, https://doi.org/10.3390/ ma9121006 (2016).

2. Sun, Y. et al. The Effect of $\mathrm{ZrO}_{2}$ Nanoparticles on the Microstructure and Properties of Sintered WC-Bronze-Based Diamond Composites. Materials 9, https://doi.org/10.3390/ma9050343 (2016).

3. Webb, S. W. Diamond retention in sintered cobalt bonds for stone cutting and drilling. Diamond and Related Materials 8, 2043-2052, https://doi.org/10.1016/S0925-9635(99)00167-3 (1999).

4. Weidenmann, K. A., Tavangar, R. \& Weber, L. Mechanical behaviour of diamond reinforced metals. Materials Science and Engineering: A 523, 226-234, https://doi.org/10.1016/j.msea.2009.05.069 (2009).

5. Xu, X., Tie, X. \& Wu, H. The effects of a Ti coating on the performance of metal-bonded diamond composites containing rare earth. International Journal of Refractory Metals and Hard Materials 25, 244-249, https://doi.org/10.1016/j.ijmhm.2006.06.002 (2007).

6. Ekimov, E. A., Suetin, N. V., Popovich, A. F. \& Ralchenko, V. G. Thermal conductivity of diamond composites sintered under high pressures. Diamond and Related Materials 17, 838-843, https://doi.org/10.1016/j.diamond.2007.12.051 (2008).

7. Feng, H., Yu, J. K. \& Tan, W. Microstructure and thermal properties of diamond/aluminum composites with TiC coating on diamond particles. Materials Chemistry and Physics 124, 851-855, https://doi.org/10.1016/j.matchemphys.2010.08.003 (2010).

8. Kidalov, S. V., Shakhov, F. M. \& Vul, A. Y. Thermal conductivity of sintered nanodiamonds and microdiamonds. Diamond and Related Materials 17, 844-847, https://doi.org/10.1016/j.diamond.2008.01.091 (2008).

9. Xue, C., Yu, J. K. \& Zhu, X. M. Thermal properties of diamond/SiC/Al composites with high volume fractions. Materials \& Design 32, 4225-4229, https://doi.org/10.1016/j.matdes.2011.04.032 (2011).

10. Chung, C.-Y., Lee, M.-T., Tsai, M.-Y., Chu, C.-H. \& Lin, S.-J. High thermal conductive diamond/Cu-Ti composites fabricated by pressureless sintering technique. Applied Thermal Engineering 69, 208-213, https://doi.org/10.1016/j.applthermaleng.2013.11.065 (2014).

11. Hu, H. \& Kong, J. Improved Thermal Performance of Diamond-Copper Composites with Boron Carbide Coating. Journal of Materials Engineering and Performance 23, 651-657, https://doi.org/10.1007/s11665-013-0780-z (2013).

12. Ma, S. et al. $\mathrm{Mo}_{2} \mathrm{C}$ coating on diamond: Different effects on thermal conductivity of diamond/Al and diamond/Cu composites. Applied Surface Science 402, 372-383, https://doi.org/10.1016/j.apsusc.2017.01.078 (2017).

13. Schubert, T. et al. Interfacial characterization of $\mathrm{Cu}$ /diamond composites prepared by powder metallurgy for heat sink applications. Scripta Materialia 58, 263-266, https://doi.org/10.1016/j.scriptamat.2007.10.011 (2008).

14. Shen, X.-Y., He, X.-B., Ren, S.-B., Zhang, H.-M. \& Qu, X.-H. Effect of molybdenum as interfacial element on the thermal conductivity of diamond/Cu composites. Journal of Alloys and Compounds 529, 134-139, https://doi.org/10.1016/j.jallcom.2012. 03.045 (2012).

15. Zhang, C., Cai, Z., Wang, R., Peng, C. \& Feng, Y. Enhancing densification capacity and properties of Al/diamond composites by partial liquid hot pressing. Surface and Coatings Technology 313, 347-354, https://doi.org/10.1016/j.surfcoat.2017.02.002 (2017).

16. Zhang, Y., Zhang, H. L., Wu, J. H. \& Wang, X. T. Enhanced thermal conductivity in copper matrix composites reinforced with titanium-coated diamond particles. Scripta Materialia 65, 1097-1100, https://doi.org/10.1016/j.scriptamat.2011.09.028 (2011).

17. Jiang, L. et al. Interfacial characteristics of diamond/aluminum composites with high thermal conductivity fabricated by squeezecasting method. Materials Characterization 106, 346-351, https://doi.org/10.1016/j.matchar.2015.06.023 (2015).

18. Zhang, C. et al. Microstructure and thermal properties of Al/W-coated diamond composites prepared by powder metallurgy. Materials \& Design 95, 39-47, https://doi.org/10.1016/j.matdes.2016.01.085 (2016).

19. Li, G. \& Xiong, B. Effects of graphene content on microstructures and tensile property of graphene-nanosheets/aluminum composites. Journal of Alloys and Compounds 697, 31-36, https://doi.org/10.1016/j.jallcom.2016.12.147 (2017).

20. Wu, J. H., Zhang, H. L., Zhang, Y., Li, J. W. \& Wang, X. T. The role of Ti coating in enhancing tensile strength of Al/diamond composites. Materials Science and Engineering: A 565, 33-37, https://doi.org/10.1016/j.msea.2012.11.124 (2013).

21. Zhang, L. et al. Microtopography and mechanical properties of vacuum hot pressing $\mathrm{Al} / \mathrm{B}_{4} \mathrm{C}$ composites. Ceramics International 44, 3048-3055, https://doi.org/10.1016/j.ceramint.2017.11.065 (2018).

22. Xu, Z. G., Jiang, L. T., Zhang, Q., Qiao, J. \& Wu, G. H. The microstructure and influence of hot extrusion on tensile properties of $\left(\mathrm{Gd}+\mathrm{B}_{4} \mathrm{C}\right) / \mathrm{Al}$ composite. Journal of Alloys and Compounds 729, 1234-1243, https://doi.org/10.1016/j.jallcom.2017.09.258 (2017).

23. Chen, H. S. et al. Microstructure evolution and mechanical properties of $\mathrm{B}_{4} \mathrm{C} / 6061 \mathrm{Al}$ neutron absorber composite sheets fabricated by powder metallurgy. Journal of Alloys and Compounds 730, 342-351, https://doi.org/10.1016/j.jallcom.2017.09.312 (2018).

24. Shen, Q. et al. Microstructure and mechanical properties of Al-7075/ $\mathrm{B}_{4} \mathrm{C}$ composites fabricated by plasma activated sintering. Journal of Alloys and Compounds 588, 265-270, https://doi.org/10.1016/j.jallcom.2013.11.089 (2014).

25. Rana, H. G., Badheka, V. J. \& Kumar, A. Fabrication of Al7075/B 4 C Surface Composite by Novel Friction Stir Processing (FSP) and Investigation on Wear Properties. Procedia Technology 23, 519-528, https://doi.org/10.1016/j.protcy.2016.03.058 (2016).

26. Sun, Y. et al. Enhanced tensile strength and thermal conductivity in copper diamond composites with $\mathrm{B}_{4} \mathrm{C}$ coating. Scientific reports 7, 10727, https://doi.org/10.1038/s41598-017-11142-y (2017).

27. Tan, Z. et al. Tailoring interfacial bonding states of highly thermal performance diamond/Al composites: Spark plasma sintering vs. vacuum hot pressing. Composites Part A: Applied Science and Manufacturing 91, 9-19, https://doi.org/10.1016/j.compositesa.2016. $09.012(2016)$

28. Wang, P. et al. Enhanced thermal conductivity and flexural properties in squeeze casted diamond/aluminum composites by processing control. Materials \& Design 88, 1347-1352, https://doi.org/10.1016/j.matdes.2015.09.048 (2015).

29. Sun, Y. et al. Reduced Graphene Oxide Reinforced 7075 Al Matrix Composites: Powder Synthesis and Mechanical Properties. Metals 7, 499, https://doi.org/10.3390/met7110499 (2017).

30. Yakel, H. Lattice expansions of two boron carbides between 12 and $940^{\circ} \mathrm{C}$. Journal of Applied Crystallography 6, 471-473, https:// doi.org/10.1107/S0021889873009246 (1973).

31. Hasselman, D. P. H. \& Johnson, L. F. Effective Thermal Conductivity of Composites with Interfacial Thermal Barrier Resistance. Journal of Composite Materials 21, 508-515, https://doi.org/10.1177/002199838702100602 (1987).

32. Yang, W. et al. Enhanced thermal conductivity in Diamond/Aluminum composites with tungsten coatings on diamond particles prepared by magnetron sputtering method. Journal of Alloys and Compounds 726, 623-631, https://doi.org/10.1016/j. jallcom.2017.08.055 (2017).

\section{Acknowledgements}

Supports from the National Natural Science Foundation of China (no. 41502344) and the China Postdoctoral Science Foundation (no. 2014M560236 and 2016T90258) are highly appreciated. 


\section{Author Contributions}

Qingnan Meng and Youhong Sun designed the experiment. Chi Zhang carried out sample preparation. Linkai $\mathrm{He}$ and carried out the XRD. Jinhao Wu carried out the SEM analysis. Ke Gao carried out the bending strength measurements, Bao-Chang Liu carried out the thermal conductivity measurements, and Chi Zhang wrote the paper. All of the authors discussed the data and commented on the paper.

\section{Additional Information}

Competing Interests: The authors declare no competing interests.

Publisher's note: Springer Nature remains neutral with regard to jurisdictional claims in published maps and institutional affiliations.

(1) Open Access This article is licensed under a Creative Commons Attribution 4.0 International License, which permits use, sharing, adaptation, distribution and reproduction in any medium or format, as long as you give appropriate credit to the original author(s) and the source, provide a link to the Creative Commons license, and indicate if changes were made. The images or other third party material in this article are included in the article's Creative Commons license, unless indicated otherwise in a credit line to the material. If material is not included in the article's Creative Commons license and your intended use is not permitted by statutory regulation or exceeds the permitted use, you will need to obtain permission directly from the copyright holder. To view a copy of this license, visit http://creativecommons.org/licenses/by/4.0/.

(c) The Author(s) 2018 